\title{
Addressing physician burnout at the systems level
}

- Cite as: CMAJ 2018 February 12;190:E174. doi: 10.1503/cmaj.109-5556

Posted on cmajnews.com on Jan. 22, 2018.

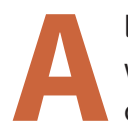
Ithough advocates for physician wellness often promote the idea of doctors improving their individual resiliency to the pressures of their profession, there is increasing recognition that addressing burnout in medicine will require changes at the systems level.

According to a recent survey of more than 15,000 doctors in the United States, about $42 \%$ of physicians report feeling burned out. The highest rates of burnout were reported in the specialties of critical care $(48 \%)$, neurology (48\%) and family medicine (47\%). enhancing communication with team huddles, developing clinician float pools to cover life events, including scores for physician satisfaction and well-being in institutional success metrics, allowing flexible schedules, and creating a wellness committee and infrastructure.

A team-based model of care helps reduce burnout because it "affords physicians the time they need to listen, think deeply and develop relationships with patients," according to the AMA. Scheduled huddles to enhance communication

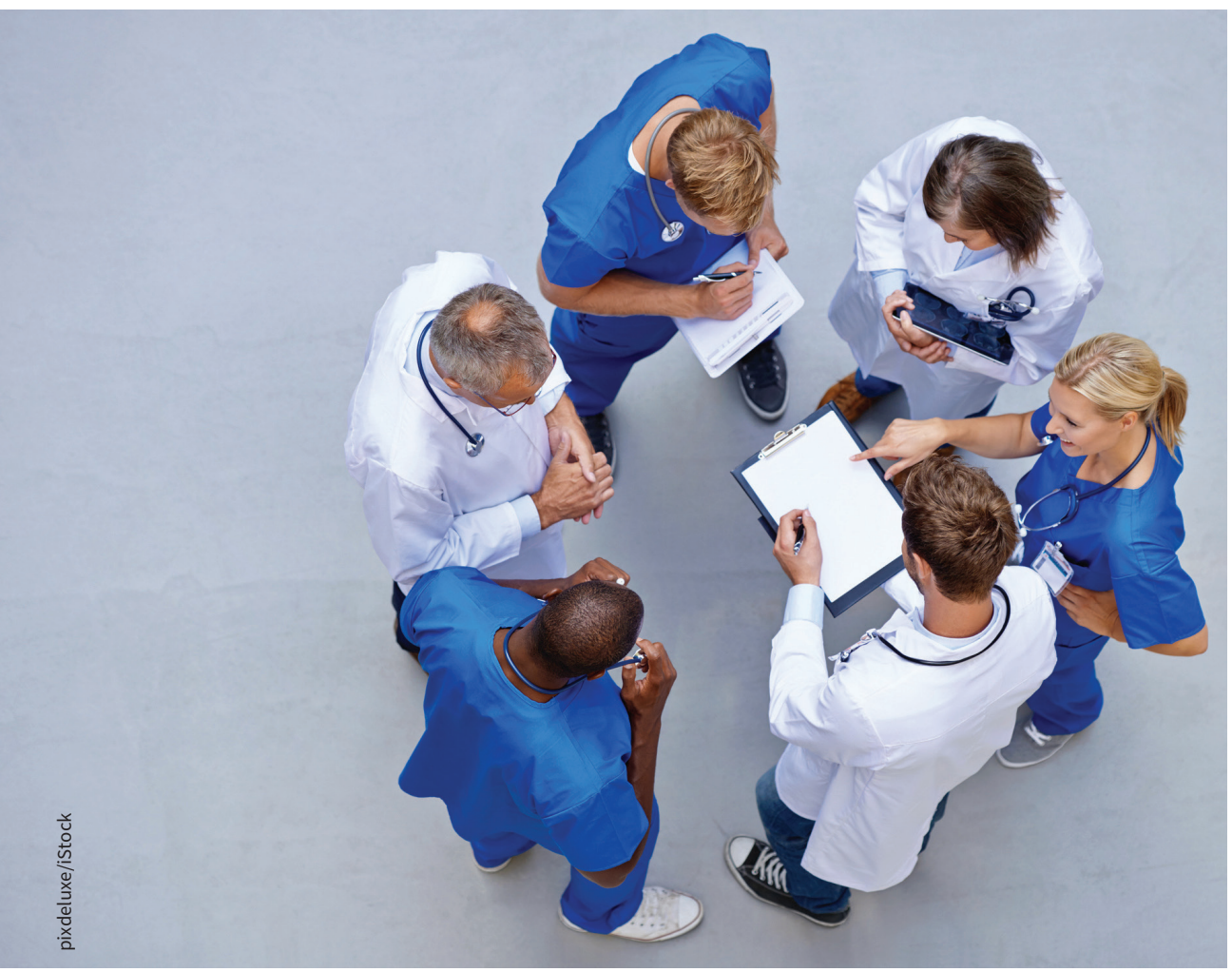

Enhancing communication in medical practice with team huddles is one systems-based approach to reducing physician burnout.

To address this problem, the American Medical Association (AMA) has recommended several systems-based approaches to reducing burnout. These approaches include implementing team-based care, between members are also important, notes the AMA, and can enhance relationships among team members while providing "an opportunity to anticipate patients' needs and prepare for changes in staffing and logistics so the day runs more smoothly."

The AMA also recommends other steps that health care organizations should take that "can result in more satisfied and productive physicians." These steps include engaging senior leadership, making a business case for physician well-being, improving workflow efficiency, reducing clerical burdens introduced by electronic health records, and measuring predictors of burnout longitudinally.

The American College of Physicians (ACP) also recently increased its efforts to address burnout, as part of its Physician Well-Being and Professional Satisfaction Initiative. "It is estimated that nearly 80 percent of the causes of physician dissatisfaction and lack of well-being are systems issues," according to ACP.

To address burnout at the systems level, the ACP promotes a "patients before paperwork" strategy. The organization has worked towards lessening the administrative complexities in medicine, which has included efforts to reduce regulatory and insurance requirements, and "eliminating other unessential tasks that detract from patient care and contribute to physician burnout."

Many of the efforts by the AMA and the $\mathrm{ACP}$ are similar to those recommended in "10 Bold Steps to Prevent Burnout in General Internal Medicine," published in the Journal of General Internal Medicine in 2014. Other steps mentioned in the paper include incorporating mindfulness into clinical practice, addressing challenging work conditions, promoting career development, and developing practice models that preserve physician work control.

"The fact that burnout is a long-term stress reaction allows time to measure and intervene," state the authors. "To combat burnout, organizations need to identify stress in its earlier stages, and choose programs to prevent burnout before it occurs."

Roger Collier, CMAJ 